\title{
The Xenopus FcR family demonstrates continually high diversification of paired receptors in vertebrate evolution Sergey V Guselnikov ${ }^{1}$, Thaminda Ramanayake ${ }^{2}$, Aleksandra Y Erilova1, Ludmila V Mechetina ${ }^{1}$, Alexander M Najakshin'1, Jacques Robert ${ }^{2}$ and Alexander V Taranin*1
}

Address: ${ }^{1}$ Institute of Cytology and Genetics, Novosibirsk, Russia and ${ }^{2}$ University of Rochester Medical Centre, Rochester, NY, USA

Email: Sergey V Guselnikov - sgus@bionet.nsc.ru; Thaminda Ramanayake - Thaminda_Ramanayake@URMC.Rochester.edu; Aleksandra Y Erilova - a_shatina@ngs.ru; Ludmila V Mechetina - lucie@bionet.nsc.ru; Alexander M Najakshin - najakshi@bionet.nsc.ru; Jacques Robert - robert@mail.rochester.edu; Alexander V Taranin* - taranin@bionet.nsc.ru

* Corresponding author

Published: 16 May 2008

BMC Evolutionary Biology 2008, 8: 148 doi:10.1 |86/I47|-2/48-8-148

This article is available from: http://www.biomedcentral.com/|47|-2/48/8//48

(c) 2008 Guselnikov et al; licensee BioMed Central Ltd.

This is an Open Access article distributed under the terms of the Creative Commons Attribution License (http://creativecommons.org/licenses/by/2.0), which permits unrestricted use, distribution, and reproduction in any medium, provided the original work is properly cited.

\begin{abstract}
Background: Recent studies have revealed an unexpected diversity of domain architecture among FcR-like receptors that presumably fulfill regulatory functions in the immune system. Different species of mammals, as well as chicken and catfish have been found to possess strikingly different sets of these receptors. To better understand the evolutionary history of paired receptors, we extended the study of FcR-like genes in amphibian representatives Xenopus tropicalis and Xenopus laevis.
\end{abstract}

Results: The diploid genome of $X$. tropicalis contains at least 75 genes encoding paired FcR-related receptors designated XFLs. The allotetraploid $X$. laevis displays many similar genes primarily expressed in lymphoid tissues. Up to 35 domain architectures generated by combinatorial joining of six Ig-domain subtypes and two subtypes of the transmembrane regions were found in XFLs. None of these variants are shared by FcR-related proteins from other studied species. Putative activating XFLs associate with the $\mathrm{FcR} \gamma$ subunit, and their transmembrane domains are highly similar to those of activating mammalian KIR-related receptors. This argues in favor of a common origin for the FcR and the KIR families. Phylogenetic analysis shows that the entire repertoires of the Xenopus and mammalian FcR-related proteins have emerged after the amphibian-amniotes split.

Conclusion: FcR- and KIR-related receptors evolved through continual species-specific diversification, most likely by extensive domain shuffling and birth-and-death processes. This mode of evolution raises the possibility that the ancestral function of these paired receptors was a direct interaction with pathogens and that many physiological functions found in the mammalian receptors were secondary acquisitions or specializations.

\section{Background}

Immune responses are regulated by a balance of opposing signals delivered from leukocyte surface molecules $[1,2]$.
In the mammalian immune system, several families of activating and inhibitory receptors form an elaborated regulatory network that tightly affects all stages of 
immune responses. The evolutionary history of this network is poorly understood. While "pairing" of receptors into the inhibitory and activating forms appears to have occurred in invertebrates, there is no clear evolutionary continuity between invertebrate and vertebrate receptor systems $[3,4]$. Furthermore, ambiguity of relationships is often observed for paired receptors from different lineages of vertebrates [5-8].

Classical Fc receptors (FCR) and killer cell immunoglobulin receptors (KIR) constitute two families that are prototypic for the paradigm of immune regulation through integration of activating and inhibitory signals. Members of each family fall into two main signaling classes. The inhibitory receptors contain ITIMs in their cytoplasmic tails, while the activating receptors associate with the ITAM-bearing transmembrane signal subunits, such as FcR $\gamma$ (FcRs) or DAP12 (KIRs). FcRs are widely expressed on various leukocyte subsets. They regulate phagocytosis, cytokines release, antibody-dependent cell mediated cytotoxicity, and antibody synthesis $[9,10]$. KIRs play a crucial role in regulation of human NK cell cytotoxicity via recognition of MHC class I antigens on the surface of target cells [11-13].

During the last decade, it has been recognized that FcRs and KIRs belong to large families comprised of structurally related yet highly diverse proteins. Thus far, eight human and six mouse FcR-like (FCRL) genes have been described [14-23]. Two of them, designated FCRLA and FCRLB according to the new nomenclature [24], are intracellular proteins composed of three Ig-like domains and a C-terminal mucin-like domain. Six human (FCRL1FCRL6) and three mouse (FCRL1, FCRL5, and FCRL6) genes code for cell surface receptors with the extracellular regions (EC) composed of two to nine Ig-like domains and intracellular regions bearing different patterns of the ITIM-, ITSM- and ITAM-like motifs. Apart from the FcRcharacteristic D1, D2 and D3 subtypes, two new structural Ig-like domain subtypes, D4 and D5, have been identified in these proteins. Furthermore, one of the novel mouse genes, FCRLS, encodes a soluble mosaic protein containing a scavenger domain $[17,22]$.

Studies of the KIR family have also revealed its considerable structural and functional heterogeneity. Human KIRlike proteins (KIRL) include cell surface receptors of the LILR (ILT/LIR/MIR) family as well as FcaR, GPVI, Nkp46, OSCAR, Lair1 and Lair2 $[25,26]$. The LILR family consists of both inhibitory and activating forms: LAIR-1 is an inhibitory receptor, LAIR2 is soluble, the others are activating. Like FcRs but unlike KIRs, the activating LILR receptors, as well as FcaR, OSCAR, NKP46, and GPVI associate with the FcR $\gamma$ subunit [27-31]. However, the transmembrane regions (TM) of activating KIRLs are structurally different from those of FcRs.

Intriguingly, the repertoires of the FcR- and KIR-related proteins are different from one species to another in higher vertebrates. For instance, each of the six human and four mouse extracellular FCRLs has a unique domain architecture $[22,24]$. Functional equivalents of KIRs in rodents are C-type lectin receptors of the Ly49 family [32]. The mouse also lacks counterparts of Fc $\alpha$ R and Lair-2 and has fewer LILR homologues described as PIRs $[25,26]$. Profound differences in the KIR and FcR families have been also revealed between mammals and birds. Recent data show that the chicken genome has more than a hundred genes for KIR-like paired receptors known as CHIRs [33-35]. At the same time, a single FcR-related gene has been detected in this species $[36,37]$.

Comparison of the 3-D structure of membrane-proximal domains of FcyRII and KIR2D demonstrated their similar folding and prompted a suggestion that the two families may have had a common origin [33]. This suggestion was made before identification of FCRLs. A later phylogenetic analysis did not provide solid support in favor of homology of five FCRL-characteristic Ig-domain subtypes with the two main domain subtypes of KIR-related receptors [5]. Nevertheless, this idea of the common ancestry of the FCR and KIR families has been revived in modified form after the recent identification of a family of paired receptors called leukocyte immune-type receptors (LITR) in catfish [6]. LITRs are composed of several domain subtypes some of which resemble the FcR-characteristic domains D1D2, whereas others are more similar to KIRL domains. Such composition of Ig domains has been proposed as ancestral for the tetrapod paired receptors [6]. However, weak sequence similarity between LITR and KIRL Ig domains, as well as the absence of the D3, D4 and D5 type domains in LITRs did not allow conclusions about definite relationships of the teleostean proteins with the higher vertebrate FcR and KIR families.

The fact that all known FcR- and KIR-related receptors are primarily expressed in cells of the immune system is consistent with their contribution to the immune regulation. However, the exact functions of all FCRLs and many KIRLs are still unknown. The ambiguity of the structural and functional evolution of FcR- and KIR-related receptors complicates our understanding of how this regulatory network is organized, which factors drives its species-specific changes and ultimately how it may be manipulated for therapeutic purposes.

To gain deeper insight into the evolution of the immunoregulation through paired receptors, we studied the FcR family in the amphibians Xenopus laevis and Xenopus trop- 
icalis. The data obtained provide evidence in favor of a common origin of the FCR and KIR families and their ceaseless diversification that appears to be caused by very strong natural selection pressure.

\section{Results \\ The FcR family is expanded in amphibians}

During our studies of the human and mouse FcR-like genes we observed that EST databases contain numerous $X$. tropicalis and $X$. laevis cDNAs encoding proteins structurally similar to mammalian FcRs and FCRLs. The degree of amino acid sequence identity ranged from 25 to $43 \%$ for different domain subtypes. We designated these genes XFL ( $\underline{X}$ enopus FcR-Like). The recent sequencing of the $X$. tropicalis genome provided an opportunity to examine the organization and structure of the XFL genes in more details. We used in silico analysis of the version 2, 3 and 4 genomic sequences deposited at the JGI website. We did not consider the consortium gene models in this survey. Direct application of gene prediction programs to genomic sequences often results in erroneous models. To overcome this pitfall, we first identified exons coding for the XFL EC and TM domains using the TBLASTN search with amino acid sequences of the corresponding $X$. tropicalis and X. laevis EST CDNAs or mammalian FcR-like proteins. The identified $X$. tropicalis sequences were used in the second round of the computational screening to reveal exons that might have been overlooked in the first round. The procedure was repeated until no novel exons were identified. The exons lacking frame-shift mutations or stop codons were examined for the presence of the AG and GT splice signals matching the phase 1 rule. Thereafter, the gene models were generated using both automatic and manual procedures. The exons for the TM regions served as the gene delimiters. This approach resulted in finding several hundred exons on 33 scaffolds. Of these, 19 scaffolds contained 1-2 exons that may either represent misassembled gene regions, gene fragments or pseudogenes. The exons on 14 other scaffolds could be arranged in at least 75 XFL genes. Fig. 1 shows the predicted organization and exon/intron arrangement of these genes. The exons encoding the signal peptides and cytoplasmic regions are not shown in this scheme because of poor accuracy of their prediction. Nevertheless, in certain cases, such exons could be delineated on the basis of alignment of the genomic sequences with the EST cDNAs. At the time, the EST databases contained $X$. tropicalis cDNAs corresponding to $13 \mathrm{XFL}$ genes. The signal peptides were invariably encoded by two exons, like in the mammalian FcR-like genes. In a fraction of XFL genes, the exons for signal peptides met the rule 30/21 bp (the length of the first/the length of the second exon), which is characteristic of mammalian FCRL1-6, Fc $\gamma$ RI and FCRLB genes. The XFL cytoplasmic regions are encoded by one to five exons.
In the mammalian genomes, FcR-like genes are linked to the genes of the CD2 family. Thus, the FCRL6 gene is a part of a conserved syntenic group that includes the SLAMF8 (BLAME), IgSF9, DUSP23, TAGLN2 and NGES1 genes [37]. We found a similar group in the scaffold 626 that contains 16 XFL genes (Fig. 1). The XFL gene 626_16 is located between two CD2-like genes, one of which shows the greatest similarity to mammalian SLAMF8 (BLAME). Xenopus homologs of the mammalian IgSF9, DUSP23, TAGLN2 and NGES1 genes are also tightly linked. This conserved synteny taken together with the results of the sequence comparisons (See additional data file 1) and phylogenetic analysis (see below) strongly supports the assignment of the XFL genes as true amphibian homologs of the mammalian FcR genes.

\section{The $X F L$ receptors are subdivided into two classes}

With a few exceptions, the predicted XFL genes code for type I cell surface receptors (Fig. 2). Their TM regions fall into two structural types that we designated TM1 and $\mathrm{TM} 2$. The characteristic feature of TM1 is the presence of a conserved NxxR motif at the N-termini. TM2 lacks charged residues. Interestingly, TM1 regions are highly homologous to the TM regions of some KIRLs such as LILRA2, PIR-A, NCR1/NKp46, GPVI, OSCAR, and FcaR (Fig. 3). All these proteins are known to associate with the FcR $\gamma$ signal subunit [27-31]. It is important to stress that TMs of classical activating FcRs are quite different, and bear a typical conserved structural motif $(\mathrm{M} / \mathrm{L}) \mathrm{Fxx}(\mathrm{D} /$ N)TxL [38]. Despite the extensive search, we did not find exons for TM regions with such a signature in the X. tropicalis genome, or in the available Xenopus EST cDNAs. Our phylogenetic analysis supports a close relationship of the TM regions of the XFL and KIRL proteins. As shown in Fig $3 \mathrm{~b}$, the NxxR motif-containing TMs and TMs of activating classical FcRs form two distinct clusters. The TM region of DAP12-associating KIR2DS, a member of the human KIR family of MHC class I-specific NK cell receptors, is not related to either of these groups.

Comparison of the $X$. tropicalis genomic and EST sequences showed that the TM1-containing proteins lack a cytoplasmic tail or have a very short one. In every such case, the TM region and the tail are encoded by the same exon. Genes with a TM2 have longer cytoplasmic tails. These tails contain one to three tyrosine-based motifs matching the consensus $\mathrm{YxxL} / \mathrm{I} / \mathrm{V}$ and are encoded by exons separated from TM exons. All these structural features are compatible with the subdivision of the XFL receptors into two functional classes, activating and inhibitory. The number of genes for each class is roughly similar and they are intermingled in the genome (Fig. 1). 

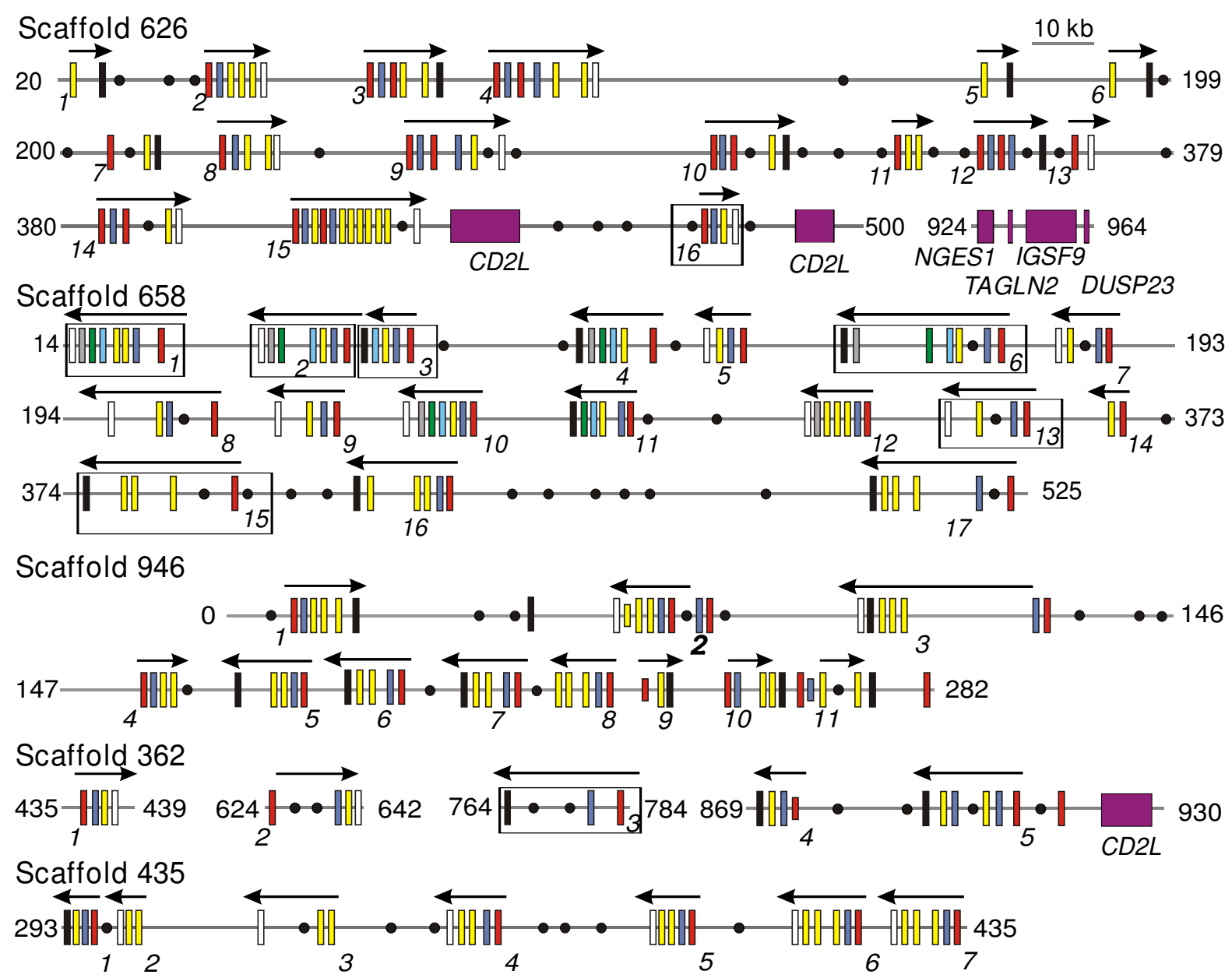

Scaffold 1131
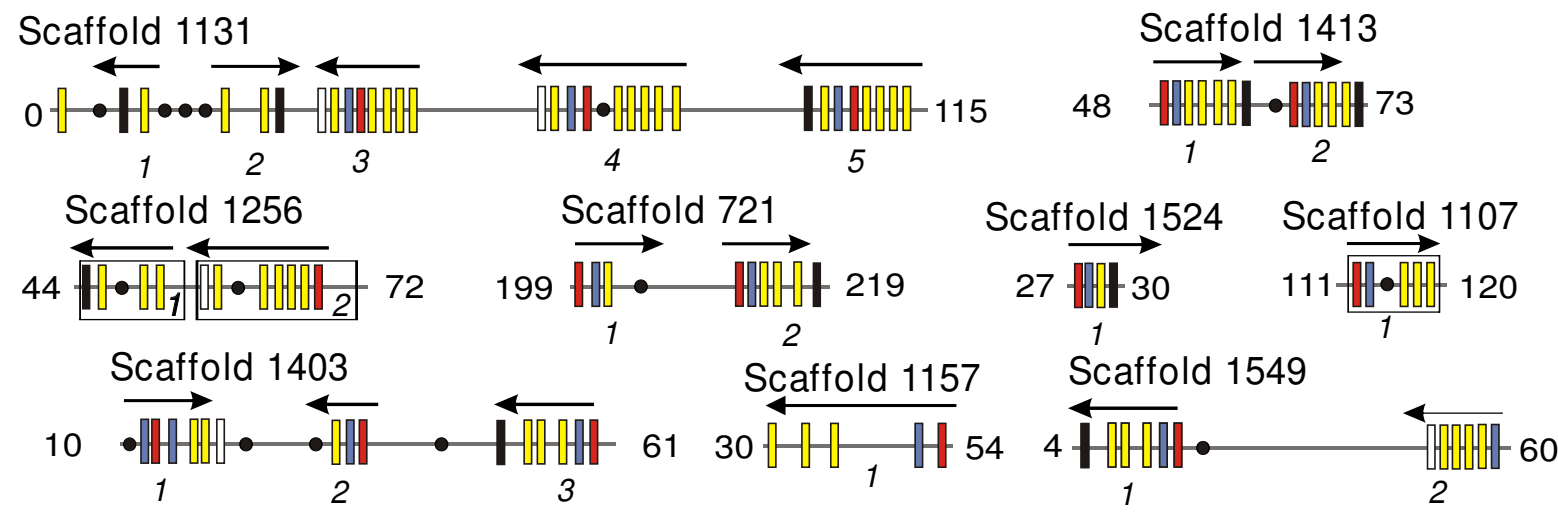

- DESIGNATIONS:

- $-(n) N$ stretch

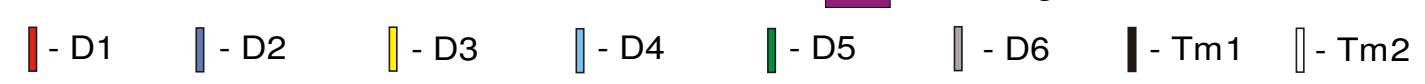

Figure I

Genomic organization of the predicted $\boldsymbol{X}$. tropicalis FcR-like genes. The exons for each particular subtype of the Iglike domains (DI-D6) are marked by a different color as indicated. Exons for TMs with the NxxR motif (TMI) are in black and those for the TM regions without charged residues (TM2) are in white. The gene models supported by $X$. tropicalis EST cDNAs are boxed. Arrows indicate transcriptional orientation. The genes are designated by their scaffold number and their consecutive position at the corresponding scaffold (version 4.I). Filled circles show position of gaps in the assembly. To conserve space, only fractions of scaffolds are shown; their borders are indicated in $\mathrm{kb}$ at the right and left sides. 

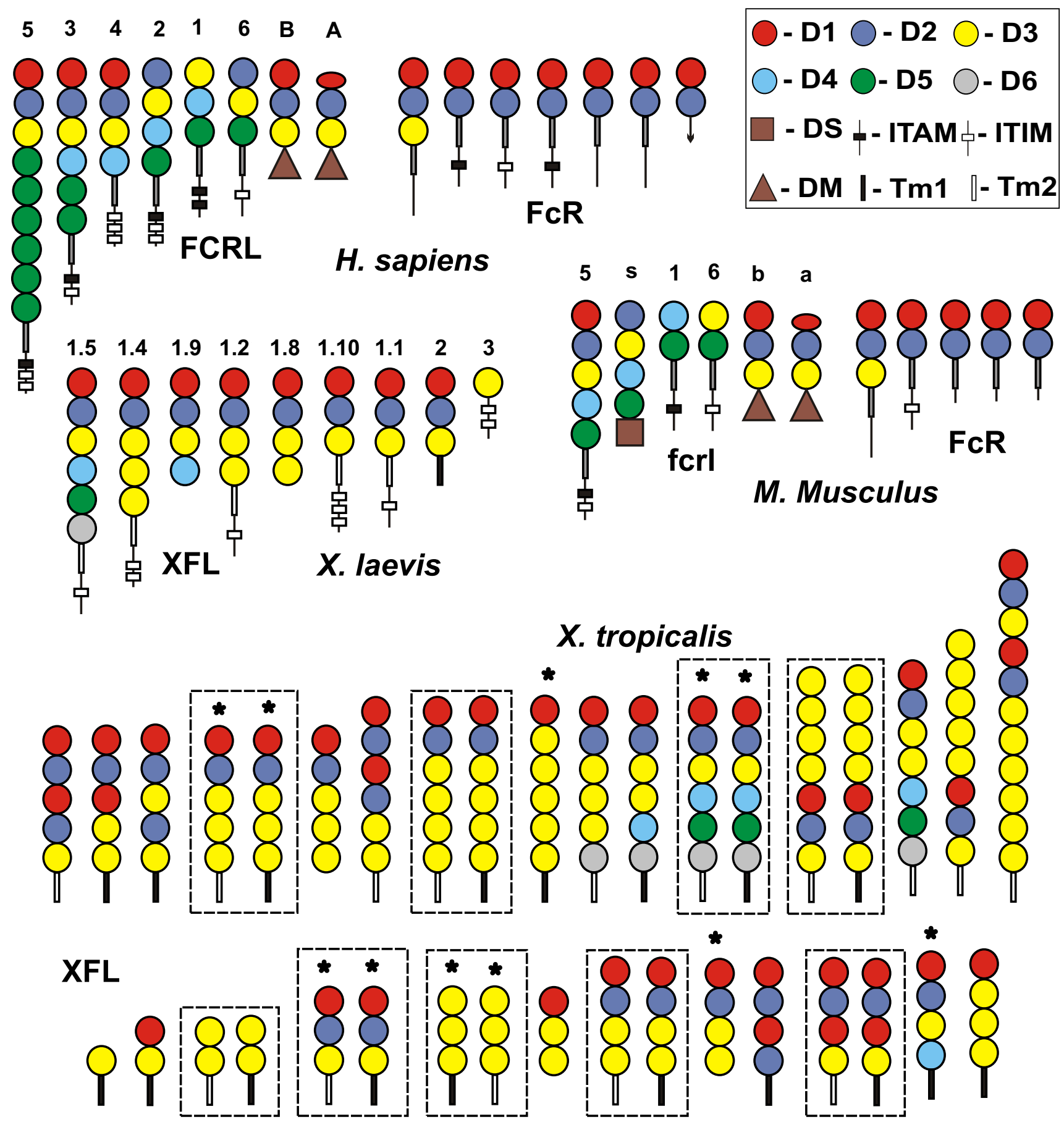

Figure 2

Schematic representation of domain architecture of human, mouse, Xenopus laevis and $X$. tropicalis FcR-like proteins. The structure of $X$. laevis molecules is deduced from cDNA sequences, whereas the structure of $X$. tropicalis molecules is predicted based on the genomic sequences and confirmed by the EST cDNA sequences (marked with asterisk). The lglike domains belonging to the DI-D6 structural subtypes are shown by circles and the TM regions by thick lines. Thin lines and rectangles designate cytoplasmic tails and $Y x x V / L / I$ motifs, respectively. The color pattern for the lg-domains subtypes and transmembrane types are as in Fig. I. Paired receptors with similar extracellular regions but distinct TM regions are boxed. 


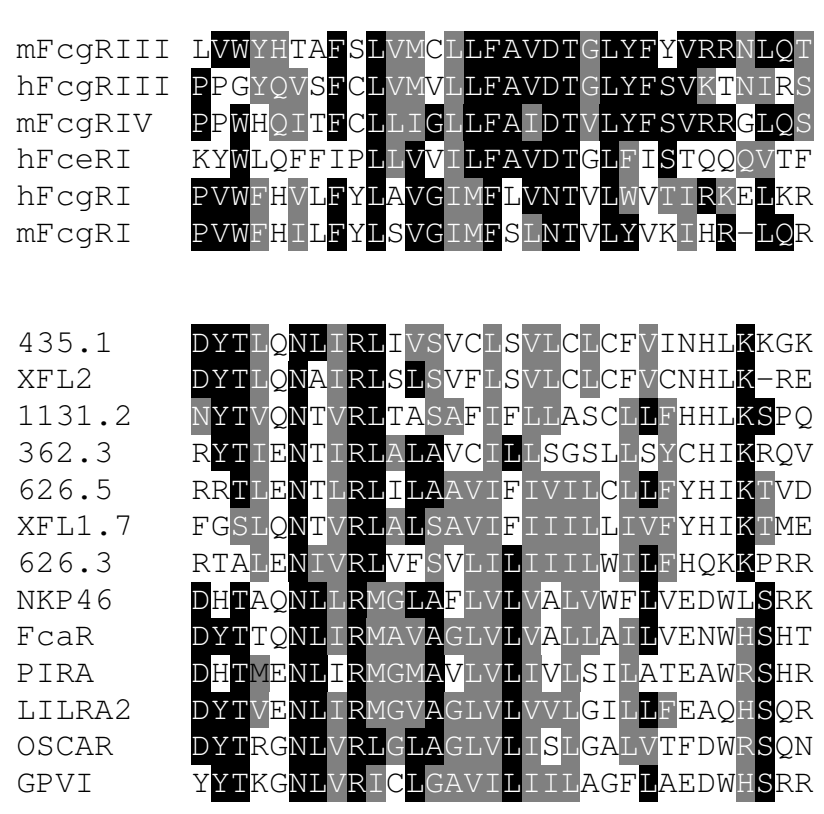

A

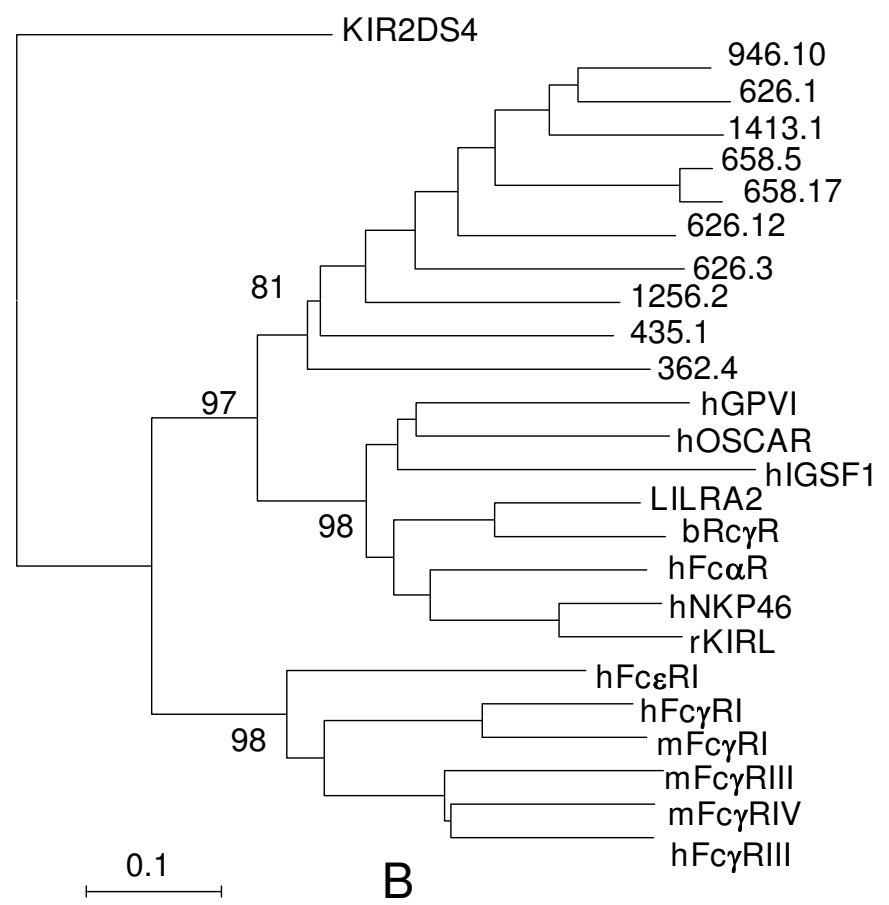

Figure 3

Alignment (A) and phylogenetic analysis (B) of the deduced TM regions of the Xenopus and mammalian FcRand KIR-like proteins. All the displayed mammalian members of the KIR family associate with FcR $\gamma$ subunit. The $X$. tropicalis genes are designated according to the scaffold number and a gene position. Identical and similar residues are shown by white letters on black and gray backgrounds, respectively. The Neighbor-Joining tree of the nucleotide sequences of the TM exons was constructed using the MEGA3 software [39]. The bootstrap values are shown.

\section{The EC regions of XFLs are highly diverse}

A remarkable feature of the predicted XFL proteins is an extraordinary diversity of their domain architectures. Overall 24 different combinations of six structural subtypes of the Ig-like domains in the EC regions of XFLs were found. Five subtypes were assigned to D1-D5 subtypes previously identified in the mammalian members of the FcR family. A sixth subtype appears to be Xenopus-specific as no close relatives were found in the protein databases. The D3 subtype domain is most frequent and may be repeated up to 7 times in a protein. Although we cannot rule out that some of the gene predictions result from genome assembly artifacts, we found high similarity between the expressed and genomic sequences. The ESTgenome comparisons showed the absence of two exons in the genomic sequences. In both cases, close inspection demonstrated the presence of gaps in the corresponding genomic regions. Eleven of 13 cDNAs fully matched our gene models. This fact, together with the absence of gaps in many predicted genes and reiteration of certain domain architectures two or more times suggest a high degree of confidence in the proposed models. Among the predicted proteins there are typical pairs with identical ectodomains and distinct TM subtypes. (Fig. 1 and 2). The EC regions of 11 XFLs are composed of D1, D2, and D3 domains, like mammalian Fc $\gamma$ RI. This is the only EC composition shared by the known mammalian and Xenopus FcR-like proteins. If we consider structural subtypes of the TM regions as distinct domains, up to 36 domain architectures may be distinguished among the XFL proteins, none of which are present among mammalian members of the FcR family.

\section{Lineage-specific expansion of Xenopus and mammalian FcR families}

While the attribution of the XFL proteins to the FCR family is unequivocal according to the reciprocal sequence comparisons and protein database analysis, it remains unclear how Xenopus and mammalian proteins are related to each other. To assess such relationships, we generated a series of phylogenetic trees with the MEGA3 software package [39]. For this purpose, amino acid sequences of the Ig domain subtypes from all the predicted XFLs were aligned (see additional data file 1). Trees were generated using the $\mathrm{NJ}$ and ME methods. To simplify the trees, the aligned blocks of D1, D2 and D3 domains were reduced by removing redundant sequences with close association. Thereafter, the sequences for all the XFL domain subtypes 
were aligned together with the domain sequences of the human proteins, and their relationships were analyzed by the same procedure. The final tree is shown on Fig 4 . The tree topology supports subdivision of the Xenopus and human Ig domains into five common (D1-D5) and one Xenopus-specific (D6) subtypes. Most importantly, the tree shows separate clustering of the Xenopus and human sequences. This branching pattern suggests that duplications of the FcR-like genes in amphibian and mammalian lineages were lineage-specific and that separation of the mammalian genes into classical FcRs and FCRLs occurred after the split of the amphibian and mammalian lineages.

The relationships among the XFL genes provide evidence for a complex pattern of family evolution in amphibians. Its detailed description is beyond the scope of the present paper and will be published separately. What is relevant to note here, is that the strong association of the amphibian sequences with each other does not necessarily correspond to high level of sequence similarity among them. The cumulative tree illustrates subdivision of the XFL D1, D2 and D3 domains into structural variants whose relationships with each other cannot be resolved. The D1, D2 and D3 domain subtypes fall into 15, 13 and 21 structural groups, respectively. The degree of sequence similarity among the group representatives (32-45\% identical residues) is in the range of sequence similarity between XFL and mammalian FCR domains. In the case of D3, the diversity is mainly derived from a small number of genes located in the scaffolds 362, 435, 1131 and 1256. For instance, the extracellular parts of the predicted proteins 1131_3 and 1131_5 are composed of five D3 domains each. These domains are subdivided into four groups. Each of five D3 domains of the XFL 1256_2 represents a distinct structural variant producing a separate branch in the tree. On the other hand, more than 50 proteins encoded by the genes of the other scaffolds have one to seven D3 domains belonging to the same group (group 1 ). This group may be further subdivided into three main subgroups 1.1, 1.2 and 1.3 and a number of individual members based on the structure of the D2 and D1 domains. For instance, the proteins encoded by the genes on the scaffold 626 have very similar D3 domains but their D1 and D2 domains fall into 8 structural variants with poorly resolved relationships. This fact strongly suggests that intergenic exon recombination was a frequent event in the evolution of the XFL family. Of ten genes containing exons for the D4, D5 or D6 domain subtypes, nine belong to the subgroup 1.1 and one to the subgroup 1.3.

Interestingly subgroups 1.1 and 1.2 differ in patterns of amino acid replacement in the D1 and D2 domains. The D2 domains of subgroup 1.2 are characterized by extensive variation in the length and sequence of the FG loop, the equivalent of CDR3 of the V-type domains (Fig. 5).
The region covering the strands $\mathrm{C}$ to $\mathrm{F}$ is well conserved. In contrast, the D2 domains of subgroup 1.1 show more variation in the region between the $\mathrm{C}^{\prime}$ and $\mathrm{F}$ strands. Their F-G region is relatively conserved. The D1 domains of the 1.1 and 1.2 subgroups also display variability at different sites (not shown) suggesting the existence of at least two classes of ligands for the group I receptors. The D1 and D2 domains are implicated in binding to IgG and IgE by classical FcRs. However, the residues known to contact the Fc portion of Ig are not conserved in the XFLs sequences,

\section{Experimental support of XFL diversity}

To gain a deeper insight into structure and expression of the XFL genes, we studied this family in X. laevis, a close relative of $X$. tropicalis. In contrast to $X$. tropicalis that has a diploid genome, $X$. laevis is an allotetraploid species. The immune system of $X$. laevis is one of the most thoroughly studied among lower vertebrates [40-42]. Five different $X$. laevis cDNAs for XFL proteins were obtained from the IMAGE consortium and sequenced. More than 30 cDNAs, 11 of which were unique, were additionally cloned from several $X$. laevis cDNA libraries using screening with an exon encoding the D3 domain of group 1 as a probe. Of 16 distinct cDNAs, 9 were full-length, the others were truncated at the $5^{\prime}$ end. Nine cDNAs encoded typical cell surface proteins containing TM2-like TM regions and cytoplasmic tails of varying length with one to three tyrosine-based motifs (Fig. 2). The amino acid sequences of two clones had short cytoplasmic tails. Their TM regions contained the NxxR motif and were assigned to the TM1 subtype. One cDNA clone encoded protein lacking TM but containing a typical cytoplasmic tail with two tyrosine-based motifs. Finally, four cDNAs coded for putative secreted proteins composed of the Ig-like domains only. At present, it is unclear whether or not the latter five clones represent alternative transcripts of genes encoding cell surface receptors.

As expected, the initial sequence comparisons demonstrated that most of X. laevis derived XFLs may be joined into group 1. Their D3 domains shared 65 to $95 \%$ identical residues with each other and with the $X$. tropicalis D3 domains of the group 1 receptors. These proteins were designated XFL1.1 - 1.14. As in the case of X. tropicalis, the $X$. laevis group 1 proteins showed variable degree of identity (35 to 85\%) in their D1 and D2 domains. Two other proteins were designated XFL2 and XFL3. Their D3 domains shared $35-45 \%$ identical residues with each other and with the D3 domains of the group 1 proteins. According to the phylogenetic analysis (not shown), the $X$. laevis XFL2 and XFL3 genes were most similar to the $X$. tropicalis 435_1 and 1131_1, 2, 3 genes respectively.

To estimate the genomic complexity of the XFL family in $X$. laevis, we performed Southern blot hybridization using 


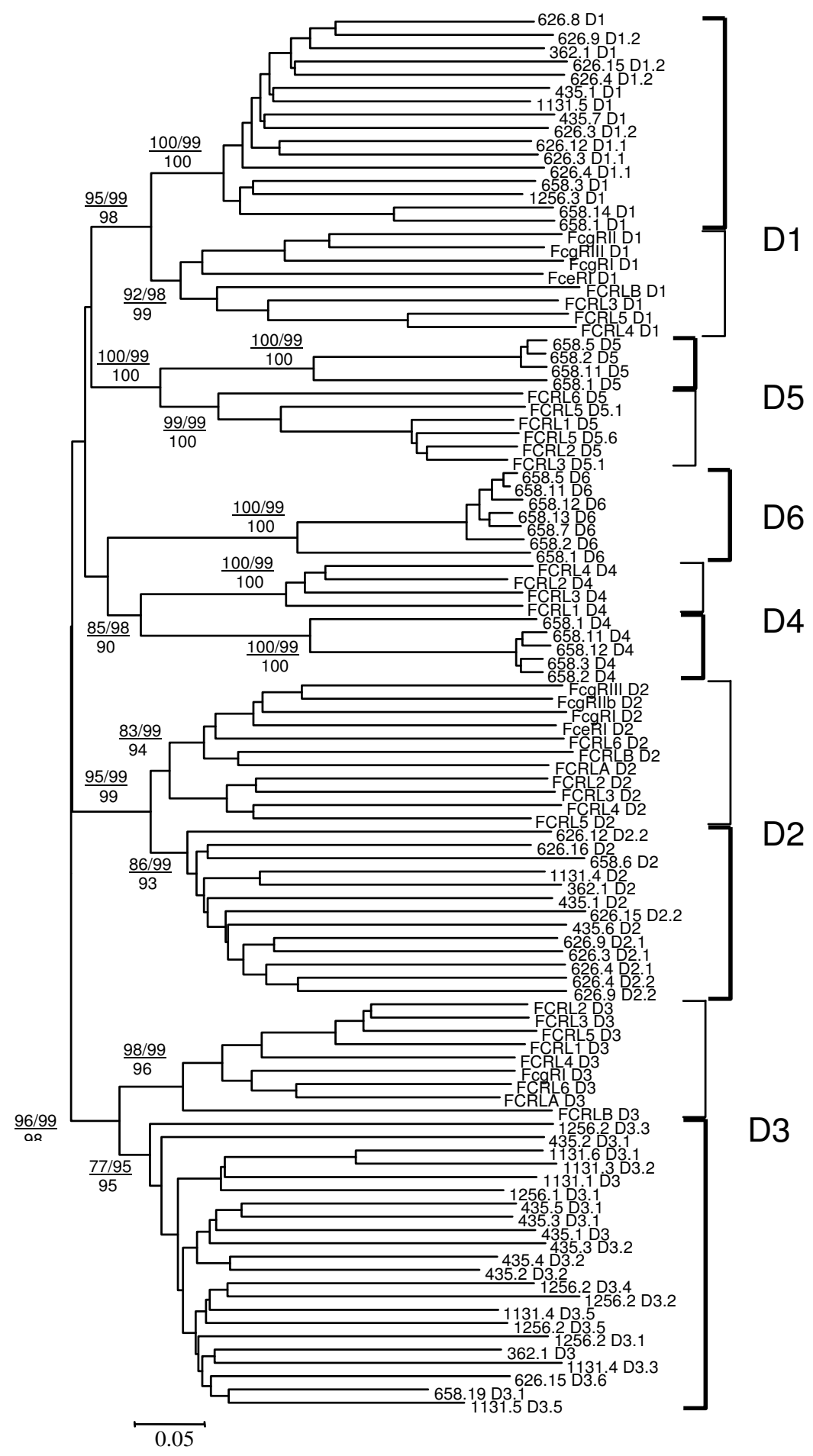

\section{Figure 4}

Neighbor-Joining tree based on the DI-D5 nucleotide sequences of $X$. tropicalis XFLs and human FcR and FCRL genes. $X$. tropicalis genes are designated according to a scaffold number and their consecutive position (See Fig. I). For genes containing multiple exons for domains of the same type these exons are numbered according to their position (i. e. D3.I-D3.3). The tree was constructed using MEGA3 software with p-distances for nucleotide sequence sites and pair-wise deletion option. The numbers on the tree represent values for the bootstrap and interior branch tests after 250 replicates. 


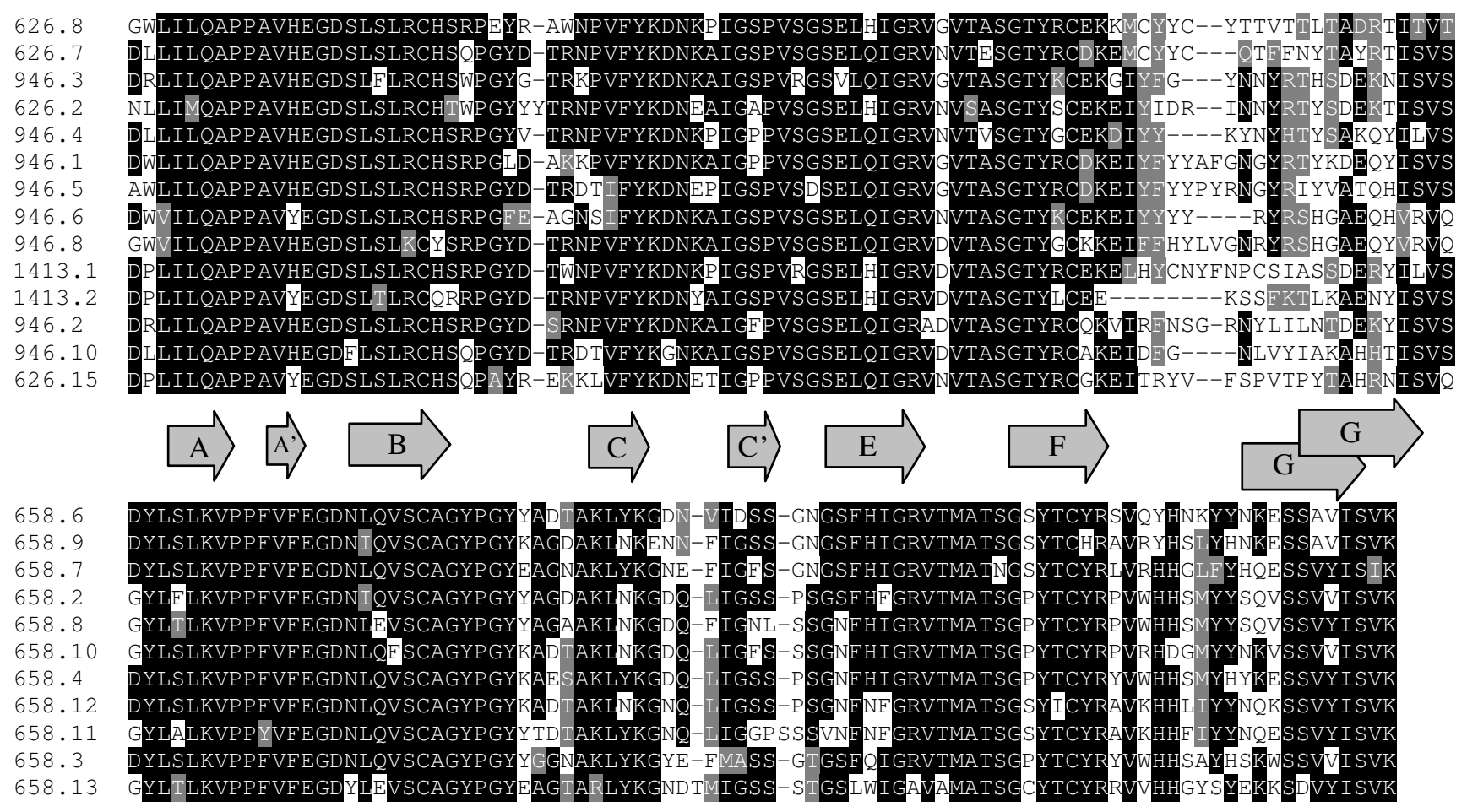

Figure 5

Alignment of deduced amino acid sequences of $X$. tropicalis D2 domains belonging to subgroups I.I and I.2. The domains are designated according to the scaffold number (version 4.I) and consecutive position of a gene encoding that particular domain (Fig. I.). Identical and similar residues are shown by white letters on black and gray backgrounds, respectively. Dashes represent gaps introduced to maximize similarity. Gray arrows indicate predicted $\beta$-strands forming Ig-like domain (A-G).

the D1-exon of XFL2 and D3-exons of the XFL1.1 and XFL3 genes as probes under non-stringent conditions. Multiple (up to 25) hybridizing bands were revealed on the blots probed with the D3-exon of the XFL1.1 gene (Fig. 6). The XFL2- and XFL3-specific probes revealed one and three hybridizing bands, respectively. These results demonstrated that the cloned XFL genes constitute only a part of the family and that, like in X. tropicalis, most of the $X$. laevis XFL genes appear to belong to the group 1 .

\section{X. laevis XFL genes are primarily expressed in lymphoid tissues}

To assess the XFL expression pattern, we performed Northern blot hybridization of total RNA from various tissues of adult frogs. The exon for D3 domain of the group I was used as a probe at low stringency conditions. As expected, Northern blotting revealed diffuse bands representing multiple gene transcripts. The highest signal intensity was observed in the spleen and thymus (Fig. 7). To examine expression patterns of the individual genes, we designed gene-specific primers for seven different XFL cDNA. To exclude possible cross matching, the 3'-untranslated sequences were mainly used for the reverse primers.
The RT-PCR analysis demonstrated that the tissue distribution of the corresponding mRNA is variable (Table 1). The transcripts of all the genes were mainly detected in lymphoid (spleen, thymus) and non-lymphoid tissues containing cells of haemopoietic origin (e.g., liver, intestine, lung). Expression of the XFL3, XFL1.10 and XFL1.12 genes was detected in brain. The tissue distribution of mRNA in tadpoles was slightly broader. In particular, all XFLs tested except 1.8, were detected in the gills which is known to be a very active immunological site owing to intense blood circulation and high exposure to antigens [43]. Furthermore, expression of the XFL1.8 gene was found only in tadpole spleen. Different pattern of the XFL transcript distribution in adults and larvae suggest that the expression of at least a proportion of the XFL genes is developmentally regulated.

\section{TMI facilitates XFL association with the FcR $\gamma$ subunit}

The presence of the NxxR motif-bearing TMs in many XFLs suggested that, like the mammalian activating KIRLs, these Xenopus receptors may require FcR $\gamma$ chain for cell surface expression and/or signal transduction. To examine whether this is the case, we generated a series of constructs 


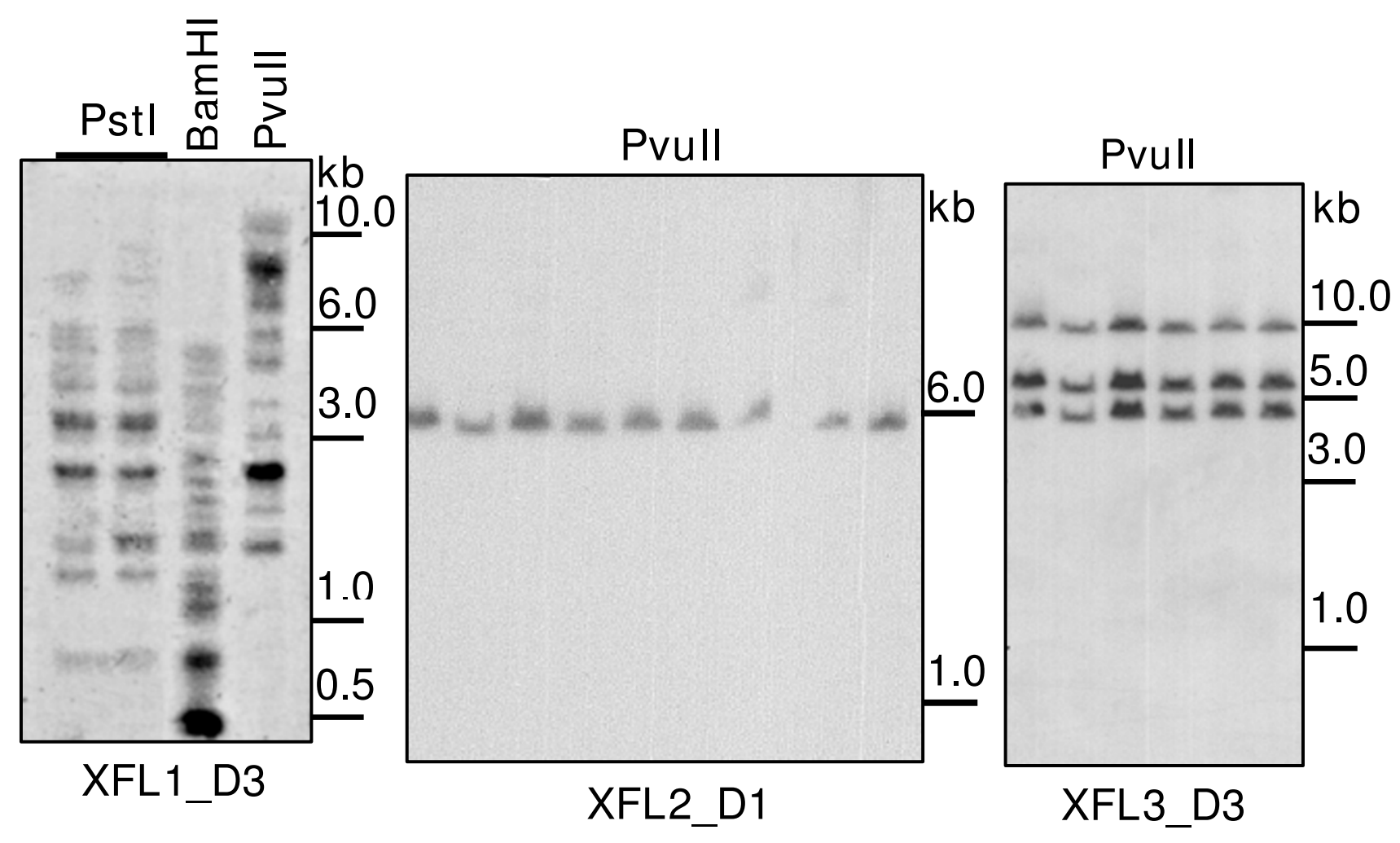

Figure 6

Southern blot analysis of Xenopus laevis genomic DNA. Hybridizing probes corresponded to the exons for DI domain of XFL2 or D3 domains of XFLI.I and XFL3.

enabling expression of XFL2, XFL1.7 and the X. laevis FcR $\gamma$ subunit as recombinant epitope-tagged proteins. XFL2 and XFL1.7 were expressed in 293T cells as recombinant hemagglutinin (HA)-tagged proteins containing either their own TM1 regions or the TM region of PDGFR. The $X$. laevis $\mathrm{FcR} \gamma$ chain was tagged with c-myc epitope. Single transfection of XFL2-HA did not induce its surface expression, and the protein accumulated intracellularly as determined by immunofluorescent microscopy of

Table I: Variations in XFL expression in X. laevis adults $(A)$ and tadpoles ( $T$, stages 46-58).

\begin{tabular}{ccccccccc}
\hline & & \multicolumn{7}{c}{ XFL } \\
\cline { 3 - 8 } & & $\mathbf{I . 2}$ & $\mathbf{I . 7}$ & $\mathbf{1 . 8}$ & $\mathbf{I . 1 0}$ & $\mathbf{I . I I}$ & $\mathbf{I . I 2}$ & $\mathbf{3}$ \\
\hline Spleen & $\mathrm{A} / \mathrm{T}$ & $+/+$ & $-/ \mathrm{NT}$ & $-/+$ & $-/+$ & $+/+$ & $+/+$ & $+/+$ \\
Thymus & $\mathrm{A} / \mathrm{T}$ & $+/+$ & $+/+$ & $-/-$ & $+/+$ & $-/-$ & $-/-$ & $+/+$ \\
Liver & $\mathrm{A} / \mathrm{T}$ & $-/-$ & $+/ \mathrm{NT}$ & $-/-$ & $+/+$ & $-/+$ & $-/ \mathrm{NT}$ & $-/-$ \\
Intestine & $\mathrm{A} / \mathrm{T}$ & $-/+$ & $+/+$ & $-/-$ & $-/+$ & $-/-$ & $+/+$ & $+/+$ \\
Lung & $\mathrm{A} / \mathrm{T}$ & $+/+$ & $-/-$ & $-/-$ & $+/+$ & $-/+$ & $-/-$ & $+/+$ \\
Brain & $\mathrm{A}$ & - & - & - & + & - & + & + \\
Gills & $\mathrm{T}$ & + & + & - & + & + & + & + \\
\hline
\end{tabular}

NT - not tested.

Results are indicative of RT-PCR performed on total RNA extracts from different tissue samples $(n=3)$. permeabilized cells. However, the surface expression of XFL2 was restored when it was co-transfected with FCR $\gamma$ (Fig. 8). In contrast to XFL2, XFL1.7-HA was targeted to the surface of the transfected cells in the absence of the adapter molecule, although its surface expression was increased two-fold in the presence of FCR $\gamma$. Both XFL2 and XFL1.7 proteins were readily expressed on the cell surface when their EC regions were fused with a TM of PDGFR. These results show that XFL molecules containing a TM1 region with the NxxR motif associate with the FcR $\gamma$ chain. The surface expression of XFL1.7 is less dependent on the presence of FcR $\gamma$ chain. This may be explained by divergent structure of their TMs. Such differences also have been observed among the FcR $\gamma$-associating KIRLs; FcR $\gamma$ is critical for surface targeting of LILRA2, but not FcaR or OSCAR $[27,29,31]$.

\section{Discussion}

Comparative studies of mammals and chicken have revealed an unexpected structural and functional variability of the paired receptor families such as FCRLs and KIRLs $[22,25,26,34-37]$. Studies have also indicated that the repertoires of these families have evolved in a species-specific manner. The evolutionary factors responsible for such diversity remain poorly understood. The recent descrip- 


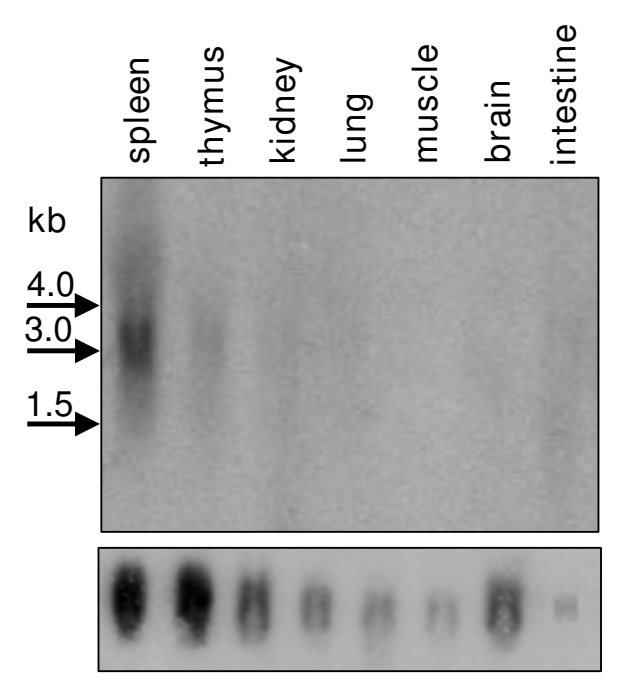

XFL1.5 D3

Figure 7

Northern blot analysis of XFL mRNA distribution in

$X$. laevis tissues. Pooled total RNA from six 6-month old frogs were hybridized under low stringency conditions with the D3 exon of XFLI.5 as an universal probe for group I XFL genes.

tion of LITRs as putative teleost counterparts of both FCRLs and KIRLs left many questions unanswered, since only a weak similarity of LITRs to the mammalian and avian receptors has been found $[6,44]$. The present study fills the gap by extending the analysis of paired receptor families to amphibians, the most primitive branch of tetrapods.

In the diploid $X$. tropicalis we have identified at least 75 genes coding for paired FcR-like cell surface receptors. The mere fact of the family expansion is not unusual. Rapid evolutionary change of a gene content known as the "expansion-contraction" or "birth-and-death" process has been documented in many families of immunity-related receptors [45]. What distinguishes the FcR family from many other paired receptor families is the extraordinary structural diversity of its members. Combinatorial joining of six Ig domain subtypes generates as many as 24 EC architectures. When we consider the TM subtypes as distinct domains, the number of the XFL domain architectures increases to 35 . None of these variants are shared by either human or mouse homologs, although five Igdomain subtypes are common for the Xenopus and mammalian proteins. Overall, 50 different domain architectures can be defined among human, mouse, and $X$. tropicalis FcR-related proteins.
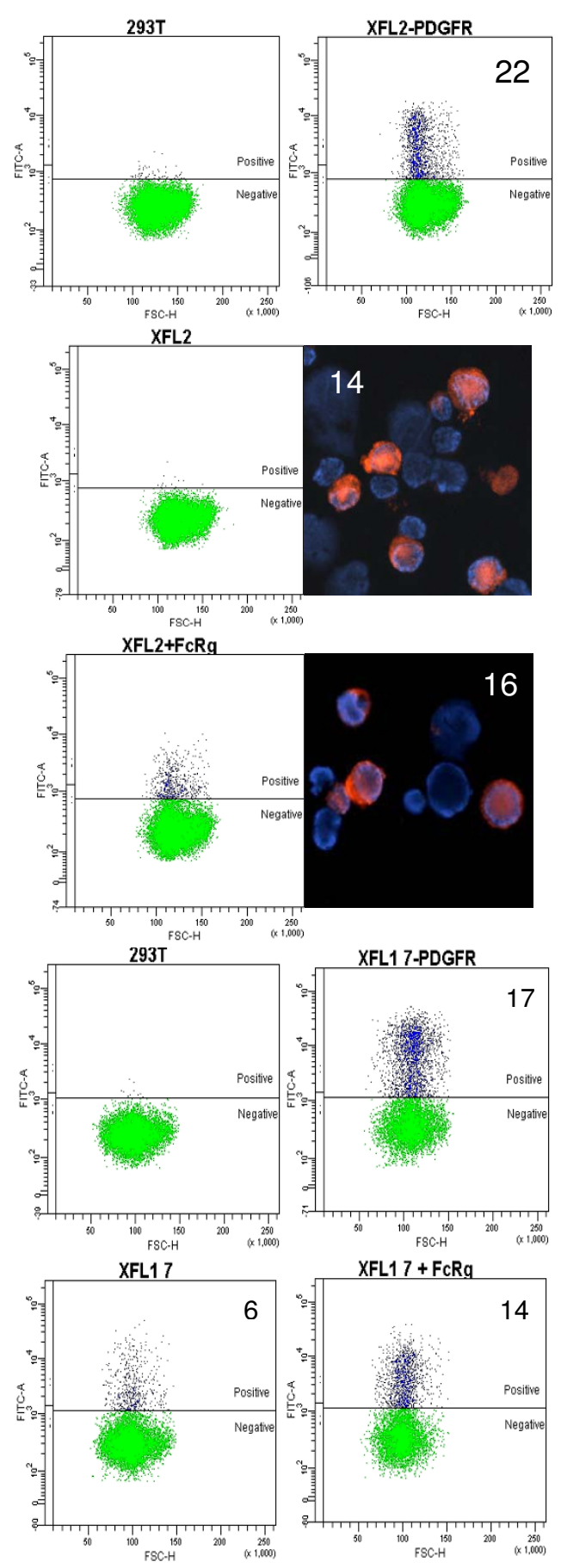

Figure 8

Requirements for the expression of XFLI.7 and

XFL2 on the cell surface. Epitope-tagged XFLI.7 or XFL2 were ectopically expressed in their native forms, or with the TM regions replaced by that of PDGFR in transiently transfected 293T cells. Effect of co-transfection with FcR $\gamma$ chain was also studied. Immunocytochemical staining of the XFL2transfected cells is shown at right. Transfection efficiency is shown as percentage of antigen-positive cells. 
Except for the D1- and D2-subtype domains no homologous structural elements were found between XFLs and catfish LITRs (not shown). Other Ig-domain subtypes composing EC of LITRs seem to be more similar to the KIRL domains. Such mixed domain composition has been suggested to predate the KIR and FcR families [6]. The XFL data are consistent with the suggestions that the FcR and KIR families share evolutionary roots $[33,46]$. A strong argument in favor of this model is the fact that activating FcRs use a peculiar TM module (TM1) to associate with FcR $\gamma$ chain that is homologous to TMs of activating mammalian KIRLs. TM1 appears to be an ancestral element of the primordial FcR/KIR family that has been lost by CHIRs, classical FCRs and KIRs, but retained by XFLs as well as Xenopus and mammalian KIRLs.

Although available data do not allow inferring the structure of the KIRL and FCRL ancestor, it is clear that the family evolved by inter- and intragenic recombinations in a species-specific way. The former mechanism gave rapid change in the number of genes per family (birth-anddeath), whereas the latter was responsible for extensive domain shuffling. The FcR-related receptors in different vertebrate species are similar in their subdivision into activating and inhibitory forms and predominant expression in lymphoid tissues. However, the ratio of inhibitory to activating members, the cellular distribution, and the exact amount and architecture of ectodomains are unique in each examined species.

What might be the evolutionary forces responsible for this degree of diversity common among the FcR- and KIRrelated receptors, and XFLs in particular? We can try to answer this question by inference from the attributed function of the actual mammalian receptors, which is to regulate immune responses. Classical FcRs regulate $\mathrm{B}$ cell responses by binding to the IgG and IgE immune complexes, whereas KIRs, or at least their inhibitory forms, regulate NK cell function by binding specifically to MHC class I molecules. However, Ig-binding appears to be a secondary or (derived) specialization, since our previous [37] and present data together with the definition of a chicken IgY receptor as a member of the CHIR family [47] strongly argue that classical FcRs have emerged after the separation of mammals and birds. MHC-recognition as a potential ancient function of FCRLs/KIRLs is more attractive. The ability to interact with classical and non-classical MHC class I molecules is a feature of some KIRLs [11-13,48-50], it has been also suggested for mammalian FCRLs [51] and catfish LITRs [46]. From this point of view the diversification of FCRL/KIRLs may have been driven by the necessity to match the rapid evolution of MHC loci under pathogen pressure of, as it has been suggested for the KIR and Ly49 gene clusters [[32,52] and [53]]. This may be the case for
XFLs too as there are at least 20 non-classical MHC class I in X. laevis [54].

There are however some inconsistencies with this scenario. First, the scope of variability of domain architectures among FCRLs seems to be excessively high relative to MHC class I molecular structure. Second, the functions of mammalian KIRLs are not limited to MHC antigen-binding. Among ligands of these receptors, there are also collagens (GPVI and LAIR1), IgA (human FcaR), IgG (bovine Fc $\gamma$ R2) and integrins (mouse Gp49B1) [55-59]. Human $\alpha 1$-B-glycoprotein, a distant secreted relative of KIRLs, binds to the cysteine-rich secretory protein 3 [60], while its opossum homolog is a snake venom metalloproteinase-neutralizing factor [61]. Due to the independent expansion of KIR-related receptors in mammals, birds [34,35] and amphibians [our unpublished data] it is difficult to determine which of these functions are truly ancient or of ancestral type. Finally, mouse Ly49 is a clear example of the self-MHC recognition served by receptors structurally different from KIRLs and FCRLs.

An alternative explanation for the extraordinary diversity of XFLs and other FCR- and KIR-related receptors may be that they are directly involved in innate immunity. Combinatorial diversity is a hallmark of the immune system and it is usually associated with recognition of pathogens. The capacity of paired receptors to directly bind to pathogens is well documented [62-66]. In the latest of these studies it has been found that mouse PIR-B, and its human relatives LILRB1 and LILRB3 recognize Staphylococcus aureus and modulate TLR-mediated inflammatory responses against this bacterium. These facts are usually interpreted in terms of adaptive coevolution of the microorganisms, which implies that the pathogen recognition is a secondary or derived function. However, the extensive variability of the FCR/KIR relatives raises the possibility that these receptors expanded primarily to fight pathogens, whereas the known immuno-regulatory functions may represent secondary acquisitions or specializations.

Depending on the nature of the pathogen and the signal properties of the receptors, it is clear that pathogen-receptor interaction may be either advantageous or detrimental for the host, and as such, may rapidly change the ratio of activating versus inhibitory receptors, as well as their respective amount and specificities. In this regard, a parallel may be drawn with the species-specific expansion of various receptor families in invertebrates that participate in innate immune responses $[67,68]$. While it may be difficult to obtain direct evidence to support this scenario, it clearly deserves attention. The elucidation of the factors responsible for the diversification of the FcR- and KIRrelated receptors may contribute to better understand 
their function and ultimately develop new therapies based on their immunoregulatory properties.

\section{Conclusion}

Our study shows that in two amphibian species Xenopus tropicalis and $X$. laevis, paired receptors have diversified into a large family of genes, XFLs, preferentially expressed in lymphoid tissues. The extracellular regions of these receptors are composed of one to eleven Ig-like domains belonging to six structural subtypes. A fraction of XFLs use a TM module (TM1) to associate with FcR $\gamma$ signaling subunit. TM1 is highly similar to TMs of activating FcR $\gamma$-associating KIRLs. This fact strongly argues in favor of a common evolutionary origin of the FCR and KIR families. The variation in number and composition of distinct Iglike and TM domain subtypes generates striking diversity of domain architectures among XFLs. Phylogenetic analysis shows that this diversity emerged in a lineage-specific manner. Classical FcRs and other known mammalian FcR-related proteins appear to be specific to mammals. The continual and extensive diversification of domain architectures in the FcR and KIR families indicates a strong selection pressure not completely consistent with the usual assumption that paired receptors have been primarily selected to regulate immune responses. We propose that FcR/KIR-related receptors might have primarily expanded as pathogen-recognizing components of innate immunity while their known physiological functions have been acquired later in a lineage-specific manner.

\section{Methods}

\section{Experimental Animals}

Adult and larval outbred Xenopus laevis were obtained from the X. laevis Research Resource for Immunobiology at the University of Rochester Medical Center [69]. Larval development stages were determined according to Nieuwkoop and Faber [70]. All animals were handled under strict laboratory and UCAR regulations. Adults and larvae were euthanized with $0.5 \%$ and $0.1 \%$ Tricaine methanesulfonate (TMS), respectively.

\section{cDNA library construction and screening}

cDNA libraries from $2 \mu \mathrm{g}$ spleen total RNA from Xenopus laevis adults or froglets (stage 60-62) were constructed using SMART cDNA Library Construction Kit (Clontech). First strand cDNA was amplified using Advantage 2 RCR Enzyme System (Clontech). Size fractionation was achieved by separation on a sepharose columns and 0.5$4 \mathrm{~kb}$ cDNAs were ligated into lambdaTriplEx2 arms and then packed with GigapackIII Gold Cloning Kit (Stratagene). Libraries containing $10^{6}$ independent recombinant clones were amplified. cDNA libraries from Xenopus laevis/ gilli LG7 hybrids (from adult spleen or tadpole spleen and liver RNA) were kindly provided by Dr. Louis Du Pasquier (University of Basel, Switzerland). All four cDNA libraries described were screened using32P-labeled PCR fragment coding for the first D3 domain of XFL1.2 (279 bp) as described by Sambrook et al. [71]. Plasmids containing cDNA inserts were recovered from isolated positive phages by in vivo excision. cDNAs were sequenced using an automated fluorescent sequencer ABI-Prizm 310 (Applied Biosystems).

\section{GenBank accessions of cDNA clones}

Xenopus EST cDNA clones dc12e01, dai46h06, daa24c04, dab24g06 and NISC_mp06d01 were obtained from the I.M.A.G.E. Consortium [72] through ATCC (USA) or Research Genetics Inc (USA), sequenced as described above and submitted to GenBank. Accession numbers for these cDNAs are [GenBank: AY293300], [GenBank: AY293303], [GenBank: AY293305], [GenBank: AY297106], and [GenBank: EF591296], respectively. [GenBank: AY293301], [GenBank: AY293302], [GenBank: AY293304], [GenBank: AY297104], [GenBank: AY297105], [GenBank: DQ367411], [GenBank: DQ367415] and [GenBank: EF431890-EF431893] accession numbers were assigned to cDNA sequences obtained through cDNA library screening.

\section{Southern blot analysis}

Genomic DNA from Xenopus erythrocytes was isolated as described by Sambrook et al. [71] and digested to completion with restriction endonucleases BamHI, HindIII or PvuII. The digested DNA (10 $\mu \mathrm{g} / \mathrm{lane})$ was separated on $1 \%$ agarose gel and transferred onto Zeta-probe nylon membranes (BioRad Laboratories) by the vacuum blotting technique in $0.4 \mathrm{M} \mathrm{NaOH}$. Hybridizations with ${ }^{32} \mathrm{P}-$ labeled probes were performed following the membrane manufacturer's recommendations. The probes were PCR amplified fragments coding for the first D3 domain of XFL1.2 (279 bp), D1 domain of XFL2 (215 bp) or D3 domain of XFL3 (239 bp).

\section{RNA extraction, CDNA synthesis, and RT-PCR amplification}

Tissue samples were homogenized in $0.8 \mathrm{~mL}$ of Trizol reagent (Invitrogen). Total RNA was extracted according to the manufacturer's protocol. A sample RNA pellet was resuspended in RNase free water and quantified with SmartSpec spectrophotometer (BioRad). 500 ng of quantified total RNA were used to synthesize cDNA with iScript first strand cDNA synthesis kit (BioRad) according to the manufacturer's protocol. Negative RT controls were run for each sample at the same time. cDNA and negative RT control samples were diluted three times to a final volume of $60 \mu \mathrm{l}$ before proceeding to PCR amplification. For each PCR reaction ( $30 \mu \mathrm{l}$ total volume) $3 \mu \mathrm{l}$ of $2 \mathrm{mM}$ dNTPs, 3 $\mu \mathrm{l}$ of $10 \times$ PCR buffer, 10 pmol of each primer, $2 \mathrm{U}$ of Taq DNA polymerase (Life Technologies), and $1 \mu$ l of cDNA were used. Then tubes were set for 35 cycles: $45 \mathrm{sec}$ at 
$95^{\circ} \mathrm{C}, 45 \mathrm{sec}$ at $56-64^{\circ} \mathrm{C}$ and $30-90 \mathrm{sec}$ at $72^{\circ} \mathrm{C}$. The following primers were used for RT-PCR: XFL1.2 forward - $5^{\prime}$ GGAAGCTATCAGTGCCAAACA 3', reverse - 5' TGAGTCTCCTGGGAGGACAGA 3', XFL1.7 forward - 5' ACACCAAAGAGGCTGCAGTTC 3', reverse - 5' GATGAGGAGCATCTTCATGGT 3', XFL1.8 forward - $5^{\prime}$ ATCGCTATCGCTCTAATGGAGC 3', reverse - 5' CAGTCTCGTGAGATTCAGCCG 3', XFL1.10 - forward 5' GACCAAGTGGACATTGTTGTGC 3', reverse - 5' TTCTCCGGCCTGTCCACCTC 3', XFL1.11 forward - 5' CTCAGGATTCCATCCAAAGTG $3^{\prime}$ reverse - $5^{\prime}$ CTTGGTCCAGTCCCGCACTG 3', XFL1.12 forward - 5' AGATGCACCCGACAAGTGAAGA 3', reverse - 5' TCAGGACAGCCAGTGCTACTG 3', XFL3 forward - 5' CTACACAAGGATACAACCCTG 3', reverse - 5' TTCTTGGGCATCACCAGAGAG 3', and as internal control, $\beta 2 \mathrm{M}$, forward - 5' CCCTTGTGGTGTAACTGTGCTC 3', reverse - 5' GCACACACCAATCAGAAAAAGGAC 3'. Negative (RT) controls were also performed with same primers to control for genomic DNA contamination.

\section{Northern blot analysis}

Total RNA (10 $\mu \mathrm{g} /$ lane) extracted and quantified as described above, was separated on $1 \%$ agarose gel with formaldehyde [71] and transferred onto Zeta-probe nylon membranes (BioRad Laboratories) by capillary transfer in $20 \times$ SSC. Hybridization with ${ }^{32}$ P-labeled probe was performed at non-stringent conditions following the membrane manufacturer's recommendations. The probe was PCR amplified fragment coding for D3 domain of XFL1.5 (282 bp). As a control for RNA integrity a probe encoding $X$. laevis $\beta$-actin was used.

\section{Constructions}

cDNA regions encoding an extracellular or extracellular plus transmembrane part of XFL2 (or XFL1.7) were cloned using primers with XmaI and PstI (or SalI) sites and ligated into pDisplay (Invitrogen) vector with an N-terminal HA epitope and with or without a C-terminal PDGFR transmembrane domain. The cDNA portions used were 45-809 bp or 45-938 bp for XFL2 cDNA [GenBank: AY293305] and 225-806 bp or 225-938 bp for XFL1.7 cDNA [GenBank: EF591296]. Complete coding region of $X$. laevis FcR $\gamma$ cDNA [GenBank: EF431895] was cloned using primers with NheI and ApaI sites and ligated into pAP-Tag5 (GenHunter) vector with a C-terminal c-myc epitope.

\section{Immunochemistry and flow cytometry}

Constructions were transiently transfected into 293T cells using Unifectin 56 (IBCH, Moscow, Russia) according to the manufacturer's protocol. Seventy two hours after they were transfected, the cells were used for immunocytochemistry and cytometric analysis. For cell surface staining, transfected cells were washed twice with Wash Buffer
(PBS, containing $1 \% \mathrm{FCS}$ and $0.1 \% \mathrm{NaN}_{3}$ ). The cells were first incubated with rabbit anti-HA (Sigma) (anti-hemagglutinin protein) in Wash Buffer for 30 min on ice. Cells were then washed three times with cold Wash Buffer and incubated with goat anti-rabbit Ig-FITC (BD Bioscience) in Wash Buffer for $30 \mathrm{~min}$ on ice. The cells were washed three times with Wash Buffer and analyzed using a microscope Axioscop 2 plus and FACSAria cytometer (BD Bioscience). For intracellular staining, transfected cells were smeared on glass slides, fixed with acetone and stained for FcR $\gamma$ subunit with anti-c-myc monoclonal antibodies (Sigma) and goat anti-mouse IgG-TexasRed (Molecular Probes).

\section{Bioinformatics tools}

Nucleotide and amino acid sequences were analyzed using utilities at the NCBI [73], EMBL [74] and BCM [75] web sites. Amino acid sequences were aligned using Clustal utilities in the MEGA3 software [39] and shaded with the BoxShade program [76]. The nucleotide and amino acid sequences of known genes were retrieved from the GenBank using ENTREZ at the NCBI [73]. The genomic sequences were retrieved from and analyzed at the Ensembl $[77,78]$ or JGI web sites [79]. Homology searches were performed using TBLASTN and TFASTA programs. The GeneScan program [80,81] and the Webgene program package $[82,83]$ were used for the automated gene structure prediction. The XFL-surrounding genes were identified using the Ensembl and JGI utilities and were verified by reciprocal sequence comparisons at the NCBI website using the BLASTP program.

Phylogenetic analysis was performed with MEGA3 [39] for nucleotide sequences of exons and amino acid sequences of domains after alignment with the CLUSTAL option. In certain cases, the CLUSTAL generated alignments were manually corrected. Phylogenetic trees were constructed using the bootstrap and interior branch tests of the Neighbor-joining (NJ) method with p-distances (proportion of differences). Minimum Evolution (ME) trees were essentially the same as the NJ trees in the major branching patterns.

\section{List of abbreviations}

Ig: Immunoglobulin; FcR: classical leukocyte Fc Receptor; FCRL: FcR-Like; KIR: Killer cell Immunoglobulin Receptor; KIRL: KIR-Like; XFL: Xenopus FcR-Like; LITR: Leukocyte Immune-Type Receptors; ITAM: Immunoreceptor Tyrosine-based Activating Motif; ITIM: Immunoreceptor Tyrosine-based Inhibitory Motif; ITSM: Immunoreceptor Tyrosine-based Switch motif; EST: Expressed Sequence Tag; EC: Extracellular region; TM: Transmembrane region. 


\section{Authors' contributions}

AVT and JR designed the study, SVG, TR and AMN performed molecular studies, AYE and AVT performed genome search and gene predictions, made sequence alignments and phylogenetic analysis, LVM carried out cell staining and flow cytometry, AVT wrote manuscript, JR helped to draft the manuscript. All authors read and approved the final manuscript.

\section{Additional material}

\section{Additional file 1}

Alignment of deduced amino acid sequences of D1-D5 domains of X. tropicalis, X. laevis XFLs and human FcR-related proteins. X. tropicalis genes are designated according to a scaffold number and their consecutive position at the corresponding scaffold (version 4.1). For proteins containing multiple domains of the same type these domains are numbered from $N$ - to C-terminus (i. e. D3.1-D3.3). X. laevis domains are designated according to the name of the cloned XFL cDNA (XFL1.1-1.12, XFL2 and XFL3) or GenBank accession number of the EST cDNA (i.e. BU903031). Identical and similar residues are shown by white letters on black and gray backgrounds, respectively. Dashes represent gaps introduced to maximize similarity.

Click here for file

[http://www.biomedcentral.com/content/supplementary/14712148-8-148-S1.pdf]

\section{Acknowledgements}

The expert animal husbandry provided by Tina Martin and David Albright is gratefully appreciated. We thank Drs. Nicolas Cohen and Andrea Bottaro for critical review of the manuscript. We would like also to thank Vadim Khaychuk for his active participation to this study.

Research was supported by the Russian Fund for Basic Research 05-0449268 (A.M.N), U.S. Civilian Research and Development Foundation RUBI-2837-NO-06 (A.V.T, J.R), RAS Program "Origin and evolution of life" (A.V.T), NIH ROI-CA-108982-02 (T.R.), NIH R24-Al-059830 and NSF MCB-0I36536 (J.R.).

\section{References}

I. Healy Jl, Goodnow CC: Positive versus negative signaling by lymphocyte antigen receptors. Annu Rev Immunol 1998, 16:645-670.

2. Ravetch JV, Lanier LL: Immune inhibitory receptors. Science 2000, 290:84-89.

3. Azumi K, De Santis R, De Tomaso A, Rigoutsos I, Yoshizaki F, Pinto MR, Marino R, Shida K, lkeda M, Arai M, Inoue Y, Shimizu T, Satoh N, Rokhsar DS, Du Pasquier L, Kasahara M, Satake M, Nonaka M: Genomic analysis of immunity in a Urochordate and the emergence of the vertebrate immune system: "waiting for Godot". Immunogenetics 2003, 55:570-58I.

4. Vogel C, Teichmann SA, Chothia C: The immunoglobulin superfamily in Drosophila melanogaster and Caenorhabditis elegans and the evolution of complexity. Development 2003, 130:6317-6328.

5. Nikolaidis N, Klein J, Nei M: Origin and evolution of the Ig-like domains present in mammalian leukocyte receptors: insights from chicken, frog, and fish homologues. Immunogenetics 2005, 57:15I-I57.

6. Stafford JL, Bengten E, Du Pasquier L, McIntosh RD, Quiniou SM, Clem LW, Miller NW, Wilson M: A novel family of diversified immunoregulatory receptors in teleosts is homologous to both mammalian Fc receptors and molecules encoded within the leukocyte receptor complex. Immunogenetics 2006, 58:758-773.

7. Cannon JP, Haire RN, Mueller MG, Litman RT, Eason DD, Tinnemore $D$, Amemiya CT, Ota T, Litman GW: Ancient divergence of a complex family of immune-type receptor genes. Immunogenetics 2006, 58:362-373.

8. Hawke NA, Yoder JA, Haire RN, Mueller MG, Litman RT, Miracle AL, Stuge T, Shen L, Miller N, Litman GW: Extraordinary variation in a diversified family of immune-type receptor genes. Proc Natl Acad Sci USA 200I, 98: I3832-13837.

9. Daeron M: Fc receptor biology. Annu Rev Immunol 1997, I5:203-234

10. Nimmerjahn F, Ravetch JV: Fc $\gamma$ receptors: old friends and new family members. Immunity 2006, 24:19-28.

II. Campbell KS, Colonna M: Human natural killer cell receptors and signal transduction. Int Rev Immunol 200I, 20:333-370.

12. Moretta L, Moretta A: Killer immunoglobulin-like receptors. Curr Opin Immunol 2004, 16:626-633.

13. Lanier LL: NK cell recognition. Annu Rev Immunol 2005, 23:225-274

14. Hatzivassiliou G, Miller I, Takizawa J, Palanisamy N, Rao PH, lida S, Tagawa S, Taniwaki M, Russo J, Neri A, Cattoretti G, Clynes R, Mendelsohn C, Chaganti RS, Dalla-Favera R: IRTAI and IRTA2, novel immunoglobulin superfamily receptors expressed in $B$ cells and involved in chromosome Iq2 I abnormalities in B cell malignancy. Immunity 200I, 14:277-289.

15. Davis RS, Wang YH, Kubagawa H, Cooper MD: Identification of a family of Fc receptor homologs with preferential B cell expression. Proc Natl Acad Sci USA 200I, 98:9772-9777.

16. Mechetina LV, Najakshin AM, Volkova OY, Guselnikov SV, Faizulin RZ, Alabyev BY, Chikaev NA, Vinogradova MS, Taranin AV: FCRL, a novel member of the leukocyte $F c$ receptor family possesses unique structural features. Eur J Immunol 2002, 32:87-96.

17. Guselnikov SV, Ershova SA, Mechetina LV, Najakshin AM, Volkova OY, Alabyev BY, Taranin AV: A family of highly diverse human and mouse genes structurally links leukocyte FcR, gp42 and PECAM-I. Immunogenetics 2002, 54:87-95.

18. Davis RS, Li H, Chen CC, Wang YH, Cooper MD, Burrows PD: Definition of an Fc receptor-related gene (FCRX) expressed in human and mouse B cells. Int Immunol 2002, I 4: 1075- 1083.

19. Davis RS, Stephan RP, Chen CC, Dennis G Jr, Cooper MD: Differential B cell expression of mouse Fc receptor homologs. Int Immunol 2004, 16:1343-1353.

20. Chikaev NA, Bykova EA, Najakshin AM, Mechetina LV, Volkova OY, Peklo MM, Shevelev AY, Vlasik TN, Roesch A, Vogt T, Taranin AV: Cloning and characterization of the human FCRL2 gene. Genomics 2005, 85:264-272.

21. Wilson TJ, Presti RM, Tassi I, Overton ET, Cella M, Colonna M: FcRL6, a new ITIM-bearing receptor on cytolytic cells, is broadly expressed by lymphocytes following HIV-I infection. Blood 2007, 109:3786-3793.

22. Davis RS: Fc receptor-like molecules. Annu Rev Immunol 2007, 25:525-560.

23. Ehrhardt GR, Leu CM, Zhang S, Aksu G, Jackson T, Haga C, Hsu JT, Schreeder DM, Davis RS, Cooper MD: Fc receptor-like proteins (FCRL): immunomodulators of $B$ cell function. Adv Exp Med Biol 2007, 596: 155-162.

24. Maltais LJ, Lovering RC, Taranin AV, Colonna M, Ravetch JV, DallaFavera R, Burrows PD, Cooper MD, Davis RS: New nomenclature for Fc receptor-like molecules. Nat Immunol 2006, 7:43 I-432.

25. Martin AM, Kulski JK, Witt C, Pontarotti P, Christiansen FT: Leukocyte Ig-like receptor complex (LRC) in mice and men. Trends Immunol 2002, 23:8I-88.

26. Kelley J, Walter L, Trowsdale J: Comparative genomics of natural killer cell receptor gene clusters. PLOS Genet 2005, I:I29-139.

27. Morton HC, Herik-Oudijk IE van den, Vossebeld P, Snijders A, Verhoeven AJ, Capel PJ, Winkel JG van de: Functional association between the human myeloid immunoglobulin $A$ Fc receptor (CD89) and FCR $\gamma$ chain. Molecular basis for CD89/FCR $\gamma$ chain association. J Biol Chem 1995, 270:2978I-29787.

28. Taylor LS, McVicar DW: Functional association of Fc\&Rl $\gamma$ with arginine(632) of paired immunoglobulin-like receptor (PIR)A3 in murine macrophages. Blood 1999, 94:1790-1796. 
29. Nakajima H, Samaridis J, Angman L, Colonna M: Human myeloid cells express an activating ILT receptor (ILTI) that associates with Fc receptor $\gamma$-chain. J Immunol 1999, 162:5-8.

30. Berlanga O, Tulasne D, Bori T, Snell DC, Miura Y, Jung S, Moroi M, Frampton J, Watson SP: The Fc receptor $\gamma$-chain is necessary and sufficient to initiate signalling through glycoprotein $\mathrm{VI}$ in transfected cells by the snake C-type lectin, convulxin. Eur J Biochem 2002, 269:295I-2960.

3I. Merck E, Gaillard C, Gorman DM, Montero-Julian F, Durand I, Zurawski SM, Menetrier-Caux C, Carra G, Lebecque S, Trinchieri G, Bates EE: OSCAR is an FcR $\gamma$-associated receptor that is expressed by myeloid cells and is involved in antigen presentation and activation of human dendritic cells. Blood 2004, 104: I386-1395.

32. Yokoyama WM, Plougastel BF: Immune functions encoded by the natural killer gene complex. Nat Rev Immunol 2003, 3:1304-3|6.

33. Dennis G Jr, Kubagawa H, Cooper MD: Paired Ig-like receptor homologs in birds and mammals share a common ancestor with mammalian Fc receptors. Proc Natl Acad Sci USA 2000 97:13245-13250

34. Viertlboeck BC, Habermann FA, Schmitt R, Groenen MA, Du Pasquier L, Gobel TW: The chicken leukocyte receptor complex: a highly diverse multigene family encoding at least six structurally distinct receptor types. J Immunol 2005, 175:385-393.

35. Laun K, Coggill P, Palmer S, Sims S, Ning Z, Ragoussis J, Volpi E, Wilson N, Beck S, Ziegler A, Volz A: The leukocyte receptor complex in chicken is characterized by massive expansion and diversification of immunoglobulin-like Loci. PLOS Genet 2006, 2:e73.

36. Taylor Al, Gould HJ, Sutton BJ, Calvert RA: The first avian Ig-like Fc receptor family member combines features of mammalian FCR and FCRL. Immunogenetics 2007, 59:323-328.

37. Fayngerts SA, Najakshin AM, Taranin AV: Species-specific evolution of the FcR family in endothermic vertebrates. Immunogenetics 2007, 59:493-506.

38. Kim MK, Huang ZY, Hwang PH, Jones BA, Sato N, Hunter S, Kim-Han TH, Worth RG, Indik ZK, Schreiber AD: Fc $\gamma$ receptor transmembrane domains: role in cell surface expression, $\gamma$ chain interaction, and phagocytosis. Blood 2003, 101:4479-4484.

39. Kumar S, Tamura K, Nei M: MEGA3: Integrated software for Molecular Evolutionary Genetics Analysis and sequence alignment. Brief Bioinform 2004, 5: I50-163.

40. Du Pasquier L, Schwager J, Flajnik MF: The immune system of Xenopus. Annu Rev Immunol 1989, 7:25I-275.

4I. Robert J, Cohen N: Evolution of immune surveillance and tumor immunity: studies in Xenopus. Immunol Rev 1998 166:231-243.

42. Du Pasquier L, Robert J, Courtet M, Mussmann R: B-cell development in the amphibian Xenopus. Immunol Rev 2000, I 75:201-2I3.

43. Cohen N, Dimarzo S, Rollins-Smith L, Barlow E, Vanderschmidt-Parson S: The ontogeny of allo tolerance and self-tolerance in larval Xenopus laevis. In Metamorphosis Edited by: Balls M, Bowns M. Oxford: Clarendon Press; 1985:388

44. Stafford JL, Wilson M, Nayak D, Ouiniou SM, Clem LW, Miller NW, Bengtén E: Identification and characterization of a FcR homolog in an ectothermic vertebrate, the channel catfish (Ictalurus punctatus). J Immunol 2006, 177:2505-17.

45. Nei M, Rooney AP: Concerted and birth-and-death evolution of multigene families. Annu Rev Genet 2005, 39:121-152.

46. Stafford JL, Bengten E, Du Pasquier L, Miller NW, Wilson M: Channel catfish leukocyte immune-type receptors contain a putative MHC class I binding site. Immunogenetics 2007, 59:77-9 I.

47. Viertlboeck BC, Schweinsberg S, Hanczaruk MA, Schmitt R, Du Pasquier L, Herberg FW, Göbel TW: The chicken leukocyte receptor complex encodes a primordial, activating, highaffinity IgY Fc receptor. Proc Natl Acad Sci USA 2007, 104:11718-23.

48. Manavalan JS, Rossi PC, Vlad G, Piazza F, Yarilina A, Cortesini R, Mancini D, Suciu-Foca N: High expression of ILT3 and ILT4 is a general feature of tolerogenic dendritic cells. Transpl Immunol 2003, II:245-258.

49. Brown D, Trowsdale J, Allen R: The LILR family: modulators of innate and adaptive immune pathways in health and disease. Tissue Antigens 2004, 64:215-225.
50. Takai T: A Novel Recognition System for MHC Class I Molecules Constituted by PIR. Adv Immunol 2005, 88:16I-192.

5I. Davis RS, Dennis G Jr, Odom MR, Gibson AW, Kimberly RP, Burrows PD, Cooper MD: Fc receptor homologs: newest members of a remarkably diverse Fc receptor gene family. Immunol Rev 2002, 190: 123-36.

52. Trowsdale J, Parham P: Mini-review: defense strategies and immunity-related genes. Eur J Immunol 2004, 34:7-17.

53. Khakoo SI, Rajalingam R, Shum BP, Weidenbach K, Flodin L, Muir DG, Canavez F, Cooper SL, Valiante NM, Lanier LL, Parham P: Rapid evolution of NK cell receptor systems demonstrated by comparison of chimpanzees and humans. Immunity 2000, I 2:687-698.

54. Flajnik MF, Kasahara M, Shum BP, Salter-Cid L, Taylor E, Du Pasquier $L$ : A novel type of class I gene organization in vertebrates: a large family of non-MHC-linked class I genes is expressed at the RNA level in the amphibian Xenopus. Embo J 1993, I 2:4385-4396.

55. Clemetson JM, Polgar J, Magnenat E, Wells TN, Clemetson KJ: The platelet collagen receptor glycoprotein $\mathrm{VI}$ is a member of the immunoglobulin superfamily closely related to $F c \alpha R$ and the natural killer receptors. J Biol Chem 1999, 274:290 I 9-29024.

56. Lebbink RJ, de Ruiter T, Adelmeijer J, Brenkman AB, van Helvoort JM, Koch M, Farndale RW, Lisman T, Sonnenberg A, Lenting PJ, Meyaard $\mathrm{L}$ : Collagens are functional, high affinity ligands for the inhibitory immune receptor LAIR-I. J Exp Med 2006, 203: I 4 I9- I 425.

57. Monteiro RC, Winkel JG Van De: IgA Fc receptors. Annu Rev Immunol 2003, 21 : 177-204.

58. Zhang G, Young JR, Tregaskes CA, Sopp P, Howard CJ: Identification of a novel class of mammalian Fc $\gamma$ receptor. J Immunol 1995, 155:|534-|54|.

59. Castells MC, Klickstein LB, Hassani K, Cumplido JA, Lacouture ME, Austen KF, Katz HR: gp49BI- $\alpha(v) \beta 3$ interaction inhibits antigen-induced mast cell activation. Nat Immunol 200I, 2:436-442.

60. Udby L, Sorensen OE, Pass J, Johnsen AH, Behrendt N, Borregaard N, Kjeldsen L: Cysteine-rich secretory protein 3 is a ligand of alpha IB-glycoprotein in human plasma. Biochemistry 2004 43:12877-12886

61. Neves-Ferreira AG, Perales J, Fox JW, Shannon JD, Makino DL, Garratt RC, Domont GB: Structural and functional analyses of DM43, a snake venom metalloproteinase inhibitor from Didelphis marsupialis serum. I Biol Chem 2002, 277:|3|29-13137.

62. Arase H, Mocarski ES, Campbell AE, Hill AB, Lanier LL: Direct recognition of cytomegalovirus by activating and inhibitory NK cell receptors. Science 2002, 296: I323-1326.

63. Arnon TI, Achdout H, Lieberman N, Gazit R, Gonen-Gross T, Katz G, Bar-llan A, Bloushtain N, Lev M, Joseph A, Kedar E, Porgador A, Mandelboim O: The mechanisms controlling the recognition of tumor- and virus-infected cells by NKp46. Blood 2004, 103:664-672.

64. Zebhauser R, Kammerer R, Eisenried A, McLellan A, Moore T, Zimmermann $W$ : Identification of a novel group of evolutionarily conserved members within the rapidly diverging murine Cea family. Genomics 2005, 86:566-580.

65. Kuespert K, Pils S, Hauck CR: CEACAMs: their role in physiology and pathophysiology. Curr Opin Cell Biol 2006, 18:565-57I.

66. Nakayama M, Underhill DM, Petersen TW, Li B, Kitamura T, Takai T, Aderem A: Paired Ig-like receptors bind to bacteria and shape TLR-mediated cytokine production. I Immunol 2007 , I 78:4250-4259.

67. Flajnik MF, Du Pasquier L: Evolution of innate and adaptive immunity: can we draw a line? Trends Immunol 2004, 25:640-644.

68. Schulenburg H, Boehnisch C, Michiels NK: How do invertebrates generate a highly specific innate immune response? Mol Immunol 2007, 44:3338-3344.

69. Xenopus laevis Research Resource for Immunobiology [http://www.urmc.rochester.edu/smd/mbi/xenopus/index.htm]

70. Nieuwkoop PD, Faber J: Normal Table of X. laevis laevis (Daudin) New York and London: Garland Publishing, Inc; 1994.

7I. Sambrook T, Fritsch EF, Maniatis T: Molecular cloning: a laboratory manual Plainview, NY: Cold Spring Harbor Laboratory Press; 1989.

72. Lennon G, Auffray C, Polymeropoulos M, Soares MB: The I.M.A.G.E. Consortium: an integrated molecular analysis of genomes and their expression. Genomics 1996, 33:15I-I52.

73. National Center for Biotechnology Information [http:// www.ncbi.nlm.nih.gov] 
74. European Bioinformatics Institute [http://www2.ebi.ac.uk]

75. Baylor College of Medicine Human Genome Sequencing Center [http://www.hgsc.bcm.tmc.edu]

76. Boxshade server [http://www.ch.embnet.org/software/ BOX form.html]

77. Ensembl Genome Browser [http://www.ensembl.org]

78. Hubbard T, Barker D, Birney E, Cameron G, Chen Y, Clark L, Cox T, Cuff J, Curwen V, Down T, Durbin R, Eyras E, Gilbert J, Hammond M, Huminiecki L, Kasprzyk A, Lehvaslaiho H, Lijnzaad P, Melsopp C, Mongin E, Pettett R, Pocock M, Potter S, Rust A, Schmidt E, Searle S, Slater G, Smith J, Spooner W, Stabenau A, Stalker J, Stupka E, UretaVidal A, Vastrik I, Clamp M: The Ensembl genome database project. Nucleic Acids Res 2002, 30:38-4I.

79. Joint Genome Institute Eukaryotic Genomics [http://
[ genome.jgi-psf.org]

80. The New GENSCAN Web Server [http://genes.mit.edu/GENS CAN.html]

81. Burge C, Karlin S: Prediction of complete gene structures in human genomic DNA. J Mol Biol 1997, 268:78-94.

82. WebGene Home Page [http://www.itb.cnr.it/sun/webgene/]

83. Milanesi L, D'Angelo D, Rogozin IB: GeneBuilder: interactive in silico prediction of gene structure. Bioinformatics 1999, |5:6|2-62|.

Publish with Bio Med Central and every scientist can read your work free of charge

"BioMed Central will be the most significant development for disseminating the results of biomedical research in our lifetime. "

Sir Paul Nurse, Cancer Research UK

Your research papers will be:

- available free of charge to the entire biomedical community

- peer reviewed and published immediately upon acceptance

- cited in PubMed and archived on PubMed Central

- yours - you keep the copyright

Submit your manuscript here:

http://www.biomedcentral.com/info/publishing_adv.asp
BioMedcentral 